\title{
JGZ-richtlijn Kindermishandeling
}

\author{
R. M. Vink · M. S. de Wolff · M. Kamphuis
}

Published online: 10 July 2017

(c) Bohn Stafleu van Loghum 2017

Samenvatting In april 2016 werd de JGZ-richtlijn Kindermishandeling gepubliceerd. Het betreft een update die de eerdere JGZ-richtlijn over kindermishandeling van 2010 vervangt. Doel van de richtlijn is om JGZ-professionals te ondersteunen bij hun taak om signalen van kindermishandeling en risico- en beschermende factoren bij jeugdigen en hun ouders na te gaan en daar adequaat naar te handelen.

Trefwoorden kindermishandeling • richtlijnen · jeugdgezondheidszorg

\section{Waarom deze richtlijn?}

Er zijn verschillende vormen van kindermishandeling: lichamelijke en emotionele mishandeling, lichamelijke en emotionele verwaarlozing, seksueel misbruik en combinaties van deze vormen. Per jaar hebben in Nederland bijna 119.000 jeugdigen van 0 tot 18 jaar te maken met kindermishandeling. Dit komt overeen met een jaarprevalentie van 34 gevallen van kindermishandeling per 1000 kinderen $(3,4 \%)$. Als we kijken naar de zogenaamde life-time prevalentie, dan zegt ongeveer een op de drie scholieren in klas 1 tot en met 4 in het voortgezet onderwijs, dat zij ooit in hun leven een of meerdere vormen van kindermishandeling heeft meegemaakt [1]. Het meemaken van kindermishandeling is schadelijk. De gevolgen kunnen direct en al tijdens de jeugd zichtbaar zijn, maar kunnen ook een leven lang doorwerken [2]. Er is een scala aan signalen die kunnen wijzen op actuele kin-

R. M. Vink $(\bowtie) \cdot$ M. S. de Wolff

TNO Child Health, Leiden, Nederland

remy.vink@tno.nl

M. Kamphuis

JGZ Zuid Holland West, Zoetermeer, Nederland dermishandeling. Signalen zijn aspecifiek; ze kunnen dus ook een 'symptoom' van iets anders zijn. Ook zijn er diverse risicofactoren die de kans op kindermishandeling vergroten. De belangrijkste risicofactoren zijn factoren die met de ouders te maken hebben, bijvoorbeeld: geweld tussen de ouders, het kind als probleem zien, hyperreactiviteit ('kort lontje') [3].

Een adequate preventie en aanpak van kindermishandeling kan veel leed voorkomen en schade beperken. De jeugdgezondheidszorg (JGZ) heeft een rol in de universele, selectieve en geïndiceerde preventie van kindermishandeling. Het is daarom belangrijk dat JGZ-professionals kennis hebben van signalen, risicoen beschermende factoren en weten hoe te handelen. Dit alles vraagt nogal wat aan competenties van de JGZ-professional. De richtlijn Kindermishandeling kan daarbij ondersteunen.

\section{Uitgangsvragen}

Aan de basis van de JGZ-richtlijn Kindermishandeling [4] lag een knelpuntenanalyse, uitgevoerd door het voormalig Kwaliteitsinstituut voor de Gezondheidszorg CBO in 2013. Deze analyse gaf vanuit het veld de belangrijkste knelpunten aan. De knelpunten zijn vertaald naar de volgende uitgangsvragen, waarop in de nieuwe richtlijn een antwoord wordt gegeven.

1. Wat is een effectieve, laagdrempelige en respectvolle methode voor JGZ-professionals om met ouders te praten over (vermoedens van) kindermishandeling?

2. Welke samenwerkingsafspraken moeten er in de jeugdketen gemaakt worden voor een snellere en effectievere opsporing en begeleiding van ouders en kinderen en hoe kunnen deze afspraken (beter) nageleefd worden? 
3. Welke kennis over ouderproblematiek hebben JGZ-professionals nodig om eerder risicofactoren te signaleren?

4. Wat moeten JGZ-professionals op welke manier registreren, zodat signalen van kindermishandeling eerder kunnen worden opgepakt?

5. Welke instrumenten of methoden zijn er voor de JGZ om (risicofactoren voor) kindermishandeling in de zwangerschap te herkennen en wat is de betrouwbaarheid van deze instrumenten?

6. Welke preventieve interventies gericht op alle risicogroepen onder zwangeren en hun eventuele partner, leiden tot betere uitkomsten bij het kind en daarmee tot een vermindering van (het risico op) kindermishandeling?

7. Welke effectieve interventies zijn er voor de JGZ om jeugdigen te betrekken bij de preventie en aanpak van kindermishandeling; wanneer kan of moet met de jeugdige alleen (zonder ouders) gesproken worden?

8. Welke ouders- en jeugdgerichte preventieve interventies zijn er om mishandeling en misbruik (door derden) in sociale situaties en het (non-)formele onderwijs te signaleren?

9. Welke kennis, vaardigheden en competenties hebben JGZ-professionals nodig voor eerder en effectiever signalering van emotionele verwaarlozing?

10. Welke effectieve (systeem)aanpak betrekt het sociale netwerk bij de begeleiding van ouders en kind(eren) bij (vermoedens van) kindermishandeling?

11. Hoe moet no-show van ouders en kind, met name bij 0 - tot 4 -jarigen, worden gedefinieerd en afgebakend en hoe moeten JGZ-professionals daarop handelen?

\section{Vraag standaard naar de veiligheid in het gezin}

Waarneming of informatie
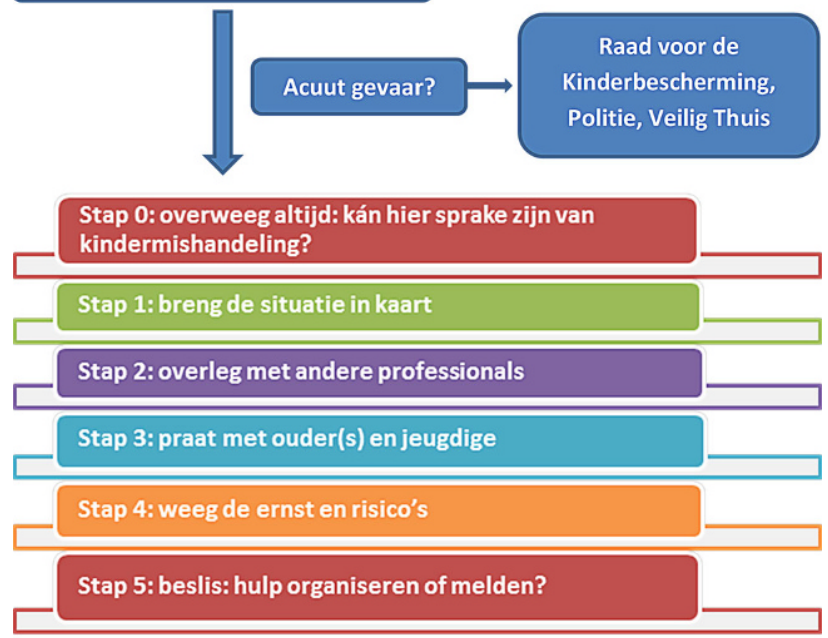

Figuur 1 Stroomdiagram.
12. Welke kennis, vaardigheden en competenties hebben JGZ-professionals nodig voor de preventie en aanpak van Vrouwelijke Genitale Verminking (VGV).

13. ... en van het Shaken Baby Syndroom (Abusive Head Trauma)?

\section{Opbouw van de richtlijn en aanbevelingen}

De richtlijn bestaat uit een eerste deel 'Algemene Thema's' met recente wetenschappelijke kennis en inzichten over aard, gevolgen en omvang, risicofactoren, beschermende factoren en signalen en over de rol van de JGZ bij het signaleren van en handelen bij (vermoedens van) kindermishandeling. De Meldcode Huiselijk Geweld en Kindermishandeling (2013) is daarvoor de kapstok (zie fig. 1). Samenwerking met andere professionals en de dialoog met ouders en jeugdigen is ook een expliciet thema. Dit eerste deel van de richtlijn sluit tevens aan bij de richtlijn Kindermishandeling voor Jeugdhulp en Jeugdbescherming [5] die in opdracht van het Nederlands Jeugdinstituut (NJi) (VWS Programma Richtlijnen) parallel door TNO werd ontwikkeld.

In het tweede deel 'Specifieke thema's' worden onderwerpen belicht zoals: verwaarlozing, preventie van kindermishandeling voor en rond de geboorte, psychiatrie bij ouders, no show, kindermishandeling door derden en vrouwelijke genitale verminking. In deze hoofdstukken worden aanbevelingen gedaan in reactie op de geprioriteerde uitgangsvragen bij de richtlijn. De richtlijn bevat tevens aanwijzingen voor registratie in het DD JGZ (digitaal dossier).

\section{Stap 0}

De Meldcode Huiselijk Geweld en Kindermishandeling vormt het kader voor het handelen als er zorgen zijn. Aan de meldcode is een 'Stap 0' toegevoegd die stelt dat de professional bij waarneming van lichamelijk letsel, aandoening, ontwikkelingsachterstand of problematisch gedrag bij de jeugdige, altijd moet overwegen of kindermishandeling dit (mede) verklaart. De JGZ-professional bespreekt dus altijd met de ouders en/of jeugdige wat zij als oorzaak zien. Is die verklaring passend, aannemelijk en consistent dan leidt dit niet tot een vermoeden of verdenking van kindermishandeling. Als daarover gerede twijfel bestaat en de zorg blijft, start de meldcode en moet dit door de JGZprofessional ook als zodanig in het DD JGZ worden geregistreerd.

Stap 0 stelt tevens dat er altijd preventief, in ieder contactmoment een beeld verkregen moet worden van de veiligheid van het kind, ook als daar geen directe aanleiding toe is door waarneming van fysieke problemen, afwijkende ontwikkeling of problematisch gedrag. Dit kan door er expliciet naar te vragen, te vragen hoe het thuis gaat, dóor te vragen en veiligheid mee te nemen in gesprekken met ouders en/of 
jeugdige volgens bijvoorbeeld SPARK [6], Samen Starten [7] of GIZ (Gezamenlijk Inschatten Zorgbehoefte) [8].

\section{Oplossingsgerichte werkwijze}

Het inschatten van de veiligheid in het gezin vraagt om specifieke competenties van de JGZ-professional. Daarom is de 'oplossingsgerichte' manier van werken $[9,10]$ een rode draad door de nieuwe richtlijn Kindermishandeling. Deze benadering laat ouders en jeugdigen in hun waarde, is niet oordelend, gaat uit van oprechte zorg en belangstelling en kijkt samen naar mogelijke vervolgstappen en oplossingen. Zonder voorbij te gaan aan problemen in het gezin, is er een sterke focus op de krachten van ieder gezinslid. Zowel ouders als jeugdigen en hun sociale netwerk worden daarom gehoord en actief betrokken in mening- en besluitvorming. Wat is hun mening en verklaring? Wat hebben zij nodig voor goed (genoeg) ouderschap?

\section{Praktijktest en randvoorwaarden voor implemen- tatie}

De praktijktest is uitgevoerd door het NJi. Er deden 40 JGZ-professionals uit twee regio's mee, van zowel de JGZ 0- tot 4-jarigen als 4- tot 18-jarigen. Men vond de richtlijn uitnodigend, prettig leesbaar en goed bruikbaar. De rol van aandachtsfunctionaris kindermishandeling is naar aanleiding van de praktijktest meer geëxpliciteerd. In de praktijktest kwam 'tijd' als belangrijke belemmerende factor naar voren bij de toepassing van de richtlijn. Nieuw is bijvoorbeeld de registratie van 'start meldcode' bij vermoedens van kindermishandeling. In de richtlijn wordt het belang van samenwerking met zowel professionals als ouders en jeugdigen, en daarmee ook van zorgvuldige registratie, benadrukt. Dit kost tijd maar is cruciaal in een exploratiefase. De richtlijn volgt daarin de meldcode Huiselijk Geweld en Kindermishandeling en is in dat opzicht niet afwijkend van de huidige werkwijze. Omdat er echter ook nieuwe inzichten en thema's opgenomen zijn in de richtlijn is op basis van de praktijktest bijscholing en intervisie aanbevolen. Daarbij bleek er vooral behoefte aan het oefenen van gesprekstechnieken, hanteren van privacyregels, kunnen inschatten van de veiligheid in een gezin en de registratie in het DD JGZ.

\section{Meer informatie?}

De JGZ-richtlijn Kindermishandeling is ontwikkeld door TNO in samenwerking met het NJi. De richt- lijn is gefinancierd door ZonMw. Voor de volledige tekst van de richtlijn, en de ondersteunende producten zoals stroomdiagram, factsheet, powerpointpresentatie, BDS-protocol, en e-learning, zie: www. jgzrichtlijnen.nl. Hier vindt $u$ ook gegevens over de auteurs en de totstandkoming van de richtlijn.

\section{Literatuur}

1. Alink L, IJzendoorn R van, Bakermans-Kranenburg M, Pannebakker F, Vogels T, Euser S. Kindermishandeling in Nederland anno 2010: De tweede nationale prevalentiestudie van mishandeling van kinderen en jeugdigen (NPM - 2010). Leiden: TNO Child Health, Universiteit Leiden, Centrum voor Gezinsstudies; 2011.

2. Felitti VJ, Anda RF, Nordenberg D, Williamson DF, Spitz AM, Edwards V, Marks JS. Relationship of childhood abuse and household dysfunction to many of the leading causes of death in adults. The adverse childhood experiences (ACE) study. Am J Prev Med. 1998;14:245-58.

3. Stith SM, Liu T, Davies LC, Boykin EL, Alder MC, Harris JM, Som A, Mc Pherson M, Drees J. Risk factors in child maltreatment: a meta-analytic review of the literature. Aggress Violent Behav. 2009;14:13-29.

4. Vink RM, Wolff MS de, Broerse A, Heerdink N, Sleuwen B van, Kamphuis M. Richtlijn Kindermishandeling voor de Jeugdgezondheidszorg. Leiden/Utrecht: TNO/NCJ. Autorisatie door AJN V\&VN Fractie Jeugd NVDA; 2016.

5. Vink RM, Wolff MS de, Broerse Kamphuis M. Richtlijn Kindermishandeling voor jeugdhulp en jeugdbescherming. Leiden/Utrecht: TNO/NJi. Autorisatie door NIP BPSW NVO; 2016.

6. Staal IIE, Hermanns JMA, Schrijvers AJP, Stel HF van. Vroegsignalering van opvoed-en opgroeiproblemen bij peuters: validiteit en betrouwbaarheid van een gestructureerd interview. Tijdschr Jeugdgezondheidsz. 2013;45(1):7-15.

7. Dijkstra N, Detmar S, Schoenmakers A, Öry F. Samen Starten: ondersteuningsbehoefte van ouders bij het opvoeden van jonge kinderen. TNO-rapport 2004, 249. Leiden: TNO Preventie en Gezondheid; 2004.

8. Bontje M. Van risicotaxatie naar gezamenlijk inschatten zorgbehoeften (GIZ). TSG. 2013;91(7):374-6.

9. Shazer S de. Creative misunderstanding: there is no escape from language. In: Giligan S, Price R (redactie). Therapeutic conversations. New York: W.W. Norton \& Co; 1993. pag. 81-90.

10. Berg IK. Family-based services: a solution-focused approach. NewYork: W.W.Norton \& Co; 1994.

R.M. Vink, socioloog/onderzoeker.

M.S. de Wolff, pedagoog/onderzoeker.

M. Kamphuis, jeugdarts. 